\title{
Galectin-3 Modulates Microglia Inflammation in vitro but Not Neonatal Brain Injury in vivo under Inflammatory Conditions
}

\author{
Karin Sävman a, b Wei Wang ${ }^{c}$ Ali Hoseinpoor Rafatic Pernilla Svedin ${ }^{c}$ \\ Syam Nairc Veronika Golubinskayac Maryam Ardalanc Kelly L. Brown ${ }^{\mathrm{c}}$ \\ Anna Karlsson-Bengtsson ${ }^{\text {e, }}$ Carina Mallard ${ }^{c}$ \\ aDepartment of Pediatrics, Sahlgrenska Academy, University of Gothenburg, Gothenburg, Sweden; begion Västra \\ Götaland, Department of Neonatology, The Queen Silvia Children's Hospital, Sahlgrenska University Hospital, \\ Gothenburg, Sweden; 'Institute of Neuroscience and Physiology, Sahlgrenska Academy, University of Gothenburg, \\ Gothenburg, Sweden; 'Department of Pediatrics, University of British Columbia and the British Columbia Children's \\ Hospital Research Institute, Vancouver, BC, Canada; 'Department of Biology and Biological Engineering, Chalmers \\ University of Technology, Gothenburg, Sweden; ${ }^{f}$ Department of Rheumatology and Inflammation Research, \\ Institute of Medicine, Sahlgrenska Academy, University of Gothenburg, Gothenburg, Sweden
}

\section{Keywords}

Brain injury $\cdot$ Cytokine $\cdot$ Hypoxia-ischemia $\cdot$ Insulin-like growth factor · Inflammation · Microglia

\begin{abstract}
Microglia may contribute to injury but may also have neuroprotective properties. Galectin-3 has immunomodulatory properties that may affect the microglia phenotype and subsequent development of injury. Galectin-3 contributes to experimental hypoxic-ischemic (HI) injury in the neonatal brain, but it is unclear if galectin-3 has similar effects on infectious and sterile inflammation. Thus, we investigated the effect of galectin-3 on microglia in vitro under normal as well as infectious and sterile inflammatory conditions, and the effect of galectin-3 on neonatal brain injury following an infectious challenge in vivo. Conditions mimicking infectious or sterile inflammation were evaluated in primary microglia cell cultures from newborn mice, using LPS (10 ng/mL) and TNF-a (100 ng/mL). The response to galectin-3 was tested
\end{abstract}

karger@karger.com www.karger.com/dne

Karger $\stackrel{\text { ' }}{5}$
(C) 2021 The Author(s)

Published by S. Karger AG, Basel

This is an Open Access article licensed under the Creative Common Attribution-NonCommercial-4.0 International License (CC BY-NC) (http://www.karger.com/Services/OpenAccessLicense), applicable to the online version of the article only. Usage and distribution for commercial purposes requires written permission. alone or together with LPS or TNF-a. Supernatants were collected $24 \mathrm{~h}$ after treatment and analyzed for 23 inflammatory mediators including pro- and anti-inflammatory cytokines and chemokines using multiplex protein analysis, as well as ELISA for MCP-1 and insulin-like growth factor (IGF)-1. Phosphorylation of proteins (AKT, ERK1/2, IKB-a, JNK, and p38) was determined in microglia cells. Neonatal brain injury was induced by a combination of LPS and HI (LPS + HI) in postnatal day 9 transgenic mice lacking functional galectin-3 and wild-type controls. LPS and TNF-a induced pro-inflammatory (9/11 vs. 9/10) and anti-inflammatory (6/6 vs. $2 / 6)$ cytokines, as well as chemokines (6/6 vs. 4/6) in a similar manner, except generally lower amplitude of the TNF-ainduced response. Galectin-3 alone had no effect on any of the proteins analyzed. Galectin-3 reduced the LPS- and TNFa-induced microglia response for cytokines, chemokines, and phosphorylation of IKB-a. LPS decreased baseline IGF-1 levels, and the levels were restored by galectin-3. Brain injury or microglia response after LPS $+\mathrm{HI}$ was not affected by galectin-3 deficiency. Galectin-3 has no independent effect 
on microglia but modulates inflammatory activation in vitro. The effect was similar under infectious and sterile inflammatory conditions, suggesting that galectin-3 regulates inflammation not just by binding to LPS or toll-like receptor-4. Galectin-3 restores IGF-1 levels reduced by LPS-induced inflammation, suggesting a potential protective effect on infectious injury. However, galectin-3 deficiency did not affect microglia activation and was not beneficial in an injury model encompassing an infectious challenge.

(C) 2021 The Author(s).

Published by S. Karger AG, Basel

\section{Introduction}

Inflammation has become increasingly recognized as an essential part of normal brain development but can also be a critical factor in processes leading to perinatal brain injury [1]. Brain injury in the perinatal period, that is, in utero, during, or after birth, can occur as a consequence of hypoxic or ischemic episodes as well as systemic infections. Noninfectious events, like hypoxiaischemia (HI), as well as systemic infections induce inflammatory reactions in the neonatal brain $[2,3]$. Clinical evidence shows that infectious inflammation may directly injure the developing brain [4] or render the infant more vulnerable to other insults [5]. Therefore, animal models of neonatal brain injury are often complemented by methods using the bacterial endotoxin LPS, alone or together with HI, to induce brain injury with associated inflammation [6]. Thus, to study inflammatory mechanisms involved in perinatal brain injury, it is important to analyze alternative ways of inducing inflammation.

Microglia are the main inflammatory cell type in the brain. Microglia proliferate and accumulate after injury induced by neonatal HI [7] as well as LPS [8] or LPS together with HI [9] and produce pro-inflammatory cytokines and chemokines that escalate inflammation. Microglia may also directly contribute to injury by the release of excitatory amino acids, oxygen free radicals, and tissue-degrading proteases. For example, microglia-derived IL-18 [10], MMP-9 [11], and IL-1 $\beta$ [12] contribute to injury in the perinatal setting. Studies have however also suggested that microglia have neuroprotective properties [13] and can be polarized into pro- or anti-inflammatory phenotypes [14]. In the immature brain, microglia depletion results in an enhanced inflammatory cytokine and chemokine response and aggravated injury after transient focal ischemia, suggesting that microglia cells are also part of the endogenous defense against brain injury [15].

Galectin-3 Modulates Microglia Inflammation
Galectin-3 is an inflammatory mediator that is expressed by microglia after adult stroke [16] as well as neonatal HI [17]. Galectin-3 has pro-inflammatory characteristics and acts as a chemokine for monocytes [18] as well as neutrophils [19], and very low doses of galectin-3 induce TNF- $\alpha$ protein in primary microglia cultures from rats [20]. Other studies indicate however that galectin-3 is expressed in alternatively activated macrophages [21] and murine microglia [14] with an anti-inflammatory and potentially protective phenotype.

Following neonatal HI, galectin-3 is mainly found in injured brain regions in a large population of nonpolarized microglia lacking the surface antigens CD86 and CD206, classically associated with inflammatory or anti-inflammatory macrophage phenotypes [22]. In the adult setting, a subpopulation of proliferating microglia that co-express galectin-3 and insulin-like growth factor (IGF)-1 has neuroprotective properties after stroke, and ablation of these cells results in aggravated injury [23]. Contrary to these findings, transgenic mice, lacking functional galectin-3, are protected from neonatal $\mathrm{HI}$ injury with the protective effect most pronounced in male mice [17]. Neuroprotection was associated with reduced expression of MMP-9 together with an increased number of microglia cells in galectin-3-deficient mice, suggesting that galectin- 3 may act by modulating microglia phenotypes under these sterile conditions. Recent studies suggest that not only the maturity of the brain but also the injury model may influence the effect of galectin-3. In a model of neonatal stroke, galectin-3 deficiency increased injury, suggesting that there can be neuroprotective properties of galectin-3 also in the immature brain [24]. Thus, investigating the immunomodulatory effects of galectin-3 may increase our knowledge of the different mechanisms that regulate microglia phenotypes and function under different inflammatory conditions.

The aim of this study was to evaluate the immunomodulatory effects of galectin-3 on murine primary microglia cells under normal and inflammatory conditions. To address the different inflammatory mechanisms important for perinatal brain injury, we used in vitro models of both infectious and sterile challenges and investigated the effect of galectin-3 on cytokine production and expression of pro-survival factors (Akt, IGF-1), as well as pro-inflammatory MAP kinases (JNK, ERK1/2, p38) and NF-kB pathway. Further, we examined microglia activation and the neuroprotective potential of galectin-3 ablation in a mouse model for infectious neonatal brain injury.

Dev Neurosci 2021;43:296-311 297 


\section{Materials and Methods}

Mice

Mice were housed and bred under specific pathogen-free conditions at Experimental Biomedicine (University of Gothenburg, Gothenburg, Sweden). Mice were housed with a 12/:12-h light/ dark cycle and with free access to water and standard laboratory rodent chow diet (B\&K, Solna, Sweden). All animal procedures were carried out in accordance with Swedish Guidelines for the Care and Use of Laboratory Animals and were approved by the Animal Ethics Committee in Gothenburg (No. 374-2009).

\section{Material}

Cell culture materials (flasks, 24-well plates, tips) were obtained from Sarstedt Inc. (Newton, NC, USA), while 70- $\mu$ m cell strainer was bought from BD (Franklin Lakes, NJ, USA). TNF- $\alpha$, Dulbecco's modified Eagle's medium (DMEM), Hanks' buffered salt solutions (HBSS), antibiotics (penicillin and streptomycin), and RIPA buffer were supplied by Sigma-Aldrich (St. Louis, MO, USA). Heat-inactivated and certified fetal bovine serum (FBS) was bought from Invitrogen-GIBCO (Waltham, MA, USA). LPS was obtained from List Biological Laboratories, Inc. (\#423; Campbell, CA, USA). Human recombinant galectin-3 was provided by Prof Anna Karlsson-Bengtsson, University of Gothenburg. The cytotoxicity detection kit (LDH) was bought from Roche Applied Science (Indianapolis, IN, USA) and BCA protein assay kit from Thermo Scientific Pierce (Waltham, MA, USA). Mouse IGF-1 and MCP-1 ELISA kits were obtained from R\&D Systems (Minneapolis, MN, USA), while Bio-Plex ProTM Mouse cytokine Assay kit (M60-009 RDPD) and Bio-PlexTM200 system were provided by Bio-Rad Laboratories Inc. (Hercules, CA, USA). In addition, a SpectraMax ${ }^{\circledR}$ Plus 384 Spectrophotometer from MD (Ramsey, MN, USA) was used. For staining histological sections, the following antibodies were used: mouse anti-microtubule-associated protein-2 (MAP-2) (Sigma-Aldrich, St. Louis, $\mathrm{MO}, \mathrm{USA})$ and mouse-anti-myelin basic protein (MBP) (SMI94R; BioSite).

\section{Microglia Cell Cultures}

Primary microglia cultures were generated, as previously described [25]. Whole brains were extracted from postnatal day (PND) 1-2 C57 Bl/6 mice (Charles River, Cologne, Germany). The cerebellum and meninges were removed, and the remaining brain transferred to ice-cold HBSS supplemented with antibiotics (100 $\mathrm{U} / \mathrm{mL}$ penicillin and $100 \mu \mathrm{g} / \mathrm{mL}$ streptomycin). The brain tissue was washed 3 times with cold HBSS/antibiotics and then transferred to DMEM with $20 \%$ FBS and supplemented with antibiotics. The brains were dissociated with gentle trituration (1-mL pipette 20-30 times) to obtain a homogeneous cell suspension that was then filtrated through a 70- $\mu$ m nylon cell strainer. The cell suspension was seeded at a density of 2 brains $/ 75-\mathrm{cm}^{3}$ flask and cultured at $37^{\circ} \mathrm{C}$ and $5 \% \mathrm{CO}_{2}$ for 7 days. The medium was then replaced by new DMEM/10\% FBS/antibiotics, and cells were cultured for an additional 7 days.

After 14 days of culture, the confluent microglial cells were selectively detached from the flasks on a rotary shaker at $150 \mathrm{rpm}$ for $3 \mathrm{~h}$ at $36^{\circ} \mathrm{C}$. The resulting cells were centrifuged and washed once with DMEM/2\% FBS/antibiotics for $10 \mathrm{~min}$ at $250 \mathrm{~g}$. The purified microglia cells were then re-suspended in DMEM/2\% FBS/antibiotics and seeded into 24 -well plates at $1 \times 10^{5}$ cells per well and then incubated for another $24 \mathrm{~h}$ prior to experiments. We have previously established that the purity of the cells obtained by this protocol is $>99 \%$ [26].

\section{In vitro Stimulation}

At the day of experiments, the cell medium was replaced by pre-warmed $500 \mu \mathrm{L}$ DMEM/antibiotics per well. Cells were stimulated with LPS $(10 \mathrm{ng} / \mathrm{mL})$, TNF- $\alpha(1,20,100 \mathrm{ng} / \mathrm{mL}), \operatorname{IL}-1 \beta(1,20$, $100 \mathrm{ng} / \mathrm{mL})$, galectin-3 $(5,50$, or $100 \mu \mathrm{g} / \mathrm{mL})$, or the combinations of LPS (10 ng/mL) or TNF- $\alpha(100 \mathrm{ng} / \mathrm{mL})$ with galectin-3 (5 or 100 $\mu \mathrm{g} / \mathrm{mL}$ ) for $24 \mathrm{~h}$. Cell culture media from each well was collected and stored at $-80^{\circ} \mathrm{C}$ until analysis. Each experiment was repeated at 3 independent times using 6 animals/repeat. Vehicle and treatment wells were situated on the same plate, and 2 samples for each treatment were analyzed for every repeat.

To avoid that analyses were affected by varying cell counts, cells were collected in RIPA buffer for protein concentration test (BCA assay kit), and all results presented were corrected for protein content. Cytotoxicity of the different treatments was tested by assessing LDH release into the supernatant (Lactate Dehydrogenase Kit; Roche) according to the manufacturer's recommendation.

\section{Inflammatory Mediator and IGF-1 Assays}

MCP-1 and IGF-1 were measured in cell culture medium by single antibody ELISA (R\&D Systems, Minneapolis, MN, USA) according to the manufacturer's instructions. Additional inflammatory mediators were measured in cell culture media by a BioPlex Pro ${ }^{\mathrm{TM}}$ Mouse cytokine Assay kit (M60-009 RDPD), allowing simultaneous detection of 23 cytokines. Cytokine results were corrected for cell protein content.

\section{Phosphoprotein Analysis}

Microglia samples for phosphoprotein analysis were treated with a Bio-Plex Cell Lysis Kit (Bio-Rad, Hercules, CA, USA) according to the protocol from the manufacturer. For detection of phosphorylation of proteins, a Bio-Plex Phospho 5-Plex Panel (X7000001RD; Bio-Rad, Hercules, CA, USA) was used according to the instructions of the manufacturer and analyzed on a Bio-Plex 200 system (Bio-Rad, Hercules, CA, USA) with Bio-Plex Manager software 6.0 (Bio-Rad, Hercules, CA, USA) as previously shown [27]. The changes in phosphorylation were calculated using the ratio between mean fluorescence of phosphorylated protein and total protein.

\section{LPS-Sensitized HI Injury, in vivo}

Galectin-3 heterozygote (+/-) mice (87.5\% C57Bl6, 12.5\% SV129) were bred to obtain littermate wild-type (WT) $+/+$ and knockout (KO) -/- mice [17]. Neonatal LPS-sensitized HI damage was induced in male and female mice at PND9 as previously described [28]. In this model, LPS (0.3 mg/kg, i.p.) is administered $14 \mathrm{~h}$ prior to unilateral HI induced by carotid ligation followed by 40-min hypoxia in $10 \%$ oxygen. This model results in brain injury in the hemisphere ipsilateral to the ligated artery, while the uninjured contralateral hemisphere serves as control. On PND16, animals were perfused in situ with saline followed by $4 \%$ paraformaldehyde fix and processed for paraffin histology [11]. Coronal sections (thickness $8 \mu \mathrm{m}$ ) were collected throughout the brain and stained for MAP-2 (1:2,000), a marker of neurons and dendrites, MBP $(1: 10,000)$ for myelin and ionized calcium-binding adapter molecule 1 (Iba1, 1:500) for microglia identification. To examine 


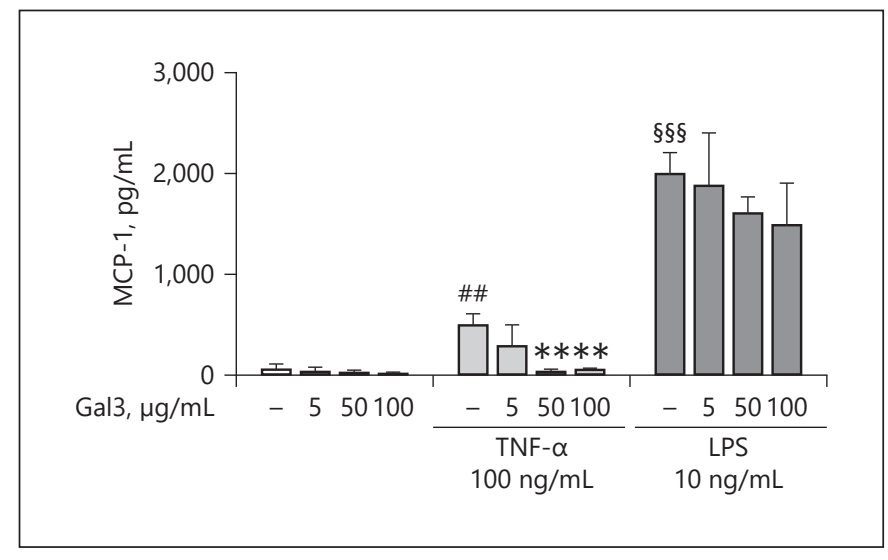

Fig. 1. Galectin-3 effects on MCP-1 protein expression following TNF- $\alpha$ and LPS exposure. Primary murine microglia cells were exposed to galectin-3 $(5,50$, or $100 \mu \mathrm{g} / \mathrm{mL})$, TNF- $\alpha(100 \mathrm{ng} / \mathrm{mL})$, or LPS $(10 \mathrm{ng} / \mathrm{mL})$ for $24 \mathrm{~h}$ or galectin-3 in combination with TNF- $\alpha$ or LPS. MCP-1 release was measured by ELISA in the cell culture medium. Data represent the average of 3 independent repeats with 2 samples representing 6 animals for each repeat. Results are presented as mean (+SEM) and analyzed by one-way ANOVA followed by Dunnet's correction; ${ }^{\$ \$ \$} p<0.001$ Veh versus LPS (10 ng/mL). ${ }^{\#} p<0.01$ Veh versus TNF-a $100 \mathrm{ng} / \mathrm{mL} ;{ }^{* *} p<$ 0.01 TNF- $\alpha$ versus TNF- $\alpha+$ galectin-3.

grey and white matter damage, every 50th brain section throughout the forebrain was analyzed, and tissue volume loss in grey and white matter, respectively, was calculated, as previously described [17].

\section{3-D Reconstruction and Analysis of Microglia}

$3-\mathrm{D}$ capturing of microglia images was performed in the ipsilateral cortex peri-infarct area $(400 \mu \mathrm{m}$ from border of brain infarct) on Ibal-stained sections at 3 brain levels with a systematic unbiased sampling principle and a section sampling fraction of 1/50 using a light microscope modified for stereology with a digital camera (DFC 295; Leica, Wetzlar, Germany) and newCAST $^{\text {TM }}$ software (Visiopharm, Hørsholm, Denmark). In animals without an infarct and in the un-damaged contralateral hemisphere, a similar cortical region was sampled. A set of Zstacks of images (step size $1 \mu \mathrm{m}$ and with middle of section as zero) was obtained using a $\times 63$ oil-immersed lens. The soma of microglia was sampled by the optical disector in the middle of section thickness. This method allowed image acquisition and capturing of more than one microglia at the same time [29]. The captured images were analyzed to obtain cell volume and sphericity by using Imaris Surface module in Imaris software (version 9.6; Bitplane AG, Zurich, Switzerland), which automatically segments and measures individual microglia. The percentage change of cell volume and sphericity between ipsi- and contralateral sides were calculated at each level as follows: [(ipsilateral side - contralateral side)/contralateral side $\times 100 \%$ ]. Three-dimensional ellipsoid plots were generated by MATLAB (R2020b) according to: https://mathworld.wolfram.com. The Imaris ellipsoid function, which includes both center and 3 axes' values (a,

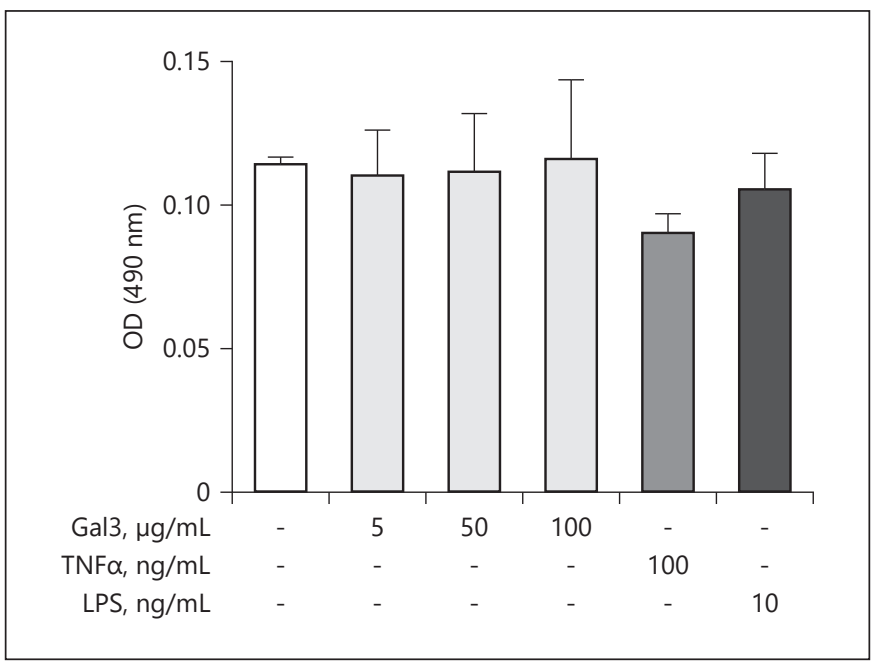

Fig. 2. LDH release is not increased following LPS, TNF- $\alpha$, and galectin-3 exposure. Primary murine microglia cells were exposed to galectin-3 $(5,50$, or $100 \mu \mathrm{g} / \mathrm{mL})$, TNF- $\alpha(100 \mathrm{ng} / \mathrm{mL})$, or LPS $(10$ $\mathrm{ng} / \mathrm{mL}$ ) for $24 \mathrm{~h}$. LDH release was measured in the cell culture medium. The figure presents the average of 3 independent repeats with 2 samples representing 6 animals for each repeat. Results are presented as mean (+SEM) and analyzed by one-way ANOVA, followed by Dunnet's correction for vehicle versus treatment.

b, c), was used to generate the corresponding plots. The mean of 3 axes' values $(\mathrm{a}, \mathrm{b}, \mathrm{c})$ per group was calculated, while all centers were assumed as zero in subplots.

\section{Statistical Data Analysis}

Results are expressed as mean \pm SEM. Statistical analysis was performed by SPSS (Released 2013, Version 24.0; IBM Corp., Armonk, NY, USA). Prior to statistical tests, normal distribution of data was checked by making a Q-Q plot of the data. The variance homogeneity of data was also examined by Levene's test. Oneway ANOVA, followed by Bonferroni's or Dunnett's post hoc corrections, was used to analyze in vitro data. Two-way ANOVA was used for analysis of in vivo data with the main effect of sex and genetic background and interaction between them. Graphs were created using Prism 8 (GraphPad Software Inc., San Diego, CA, USA). A $p$ value $<0.05$ was considered statistically significant.

\section{Results}

\section{Induction of Sterile Inflammation in vitro}

In the first set of experiments, we compared the inflammatory response following TNF- $\alpha$, IL-1 $\beta$, and LPS in primary microglia cultures, thus establishing models for infectious and sterile inflammation in vitro. The inflammatory response was evaluated by comparing 


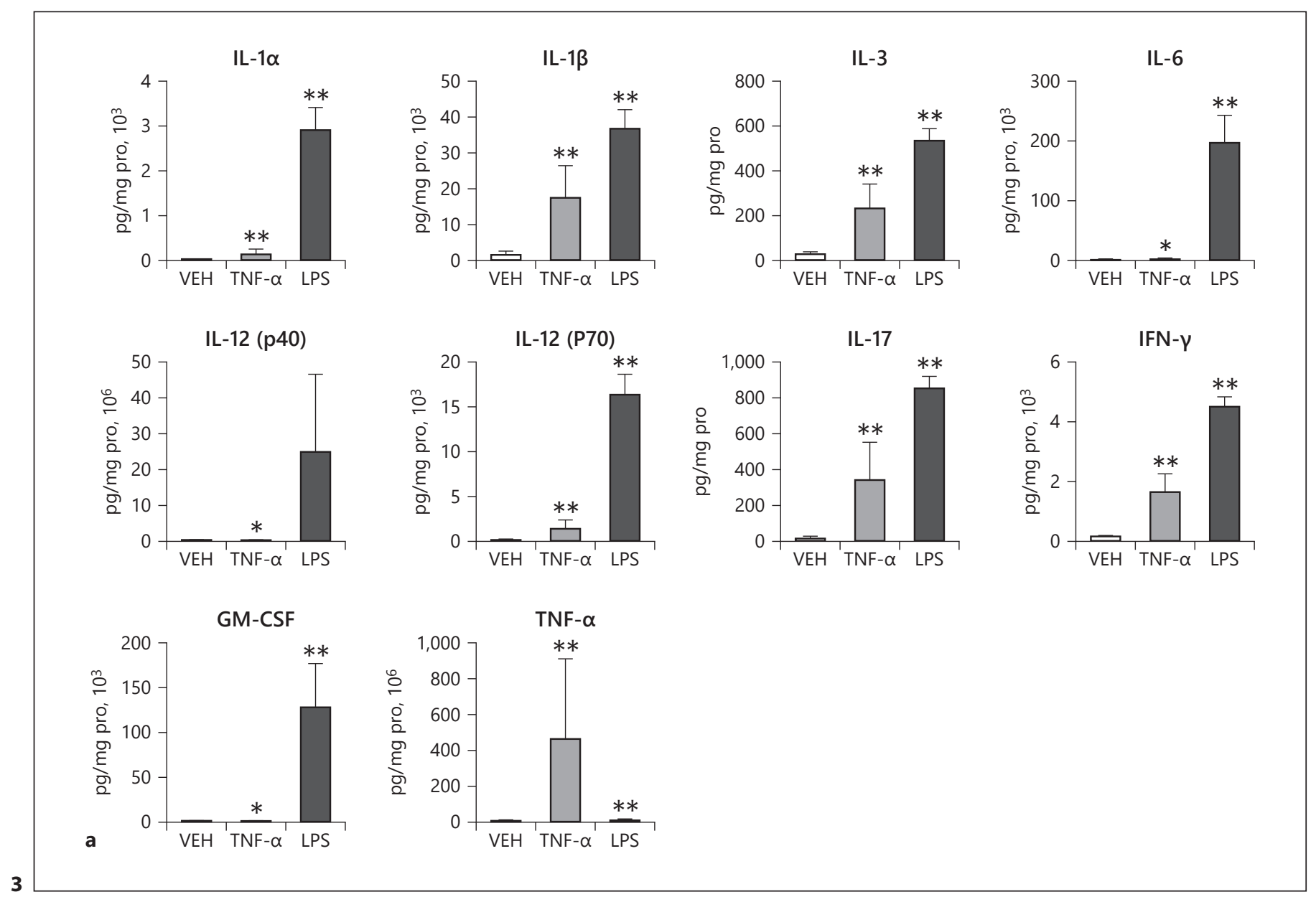

(Figure continued on next page.)

the LPS (10 $\mathrm{ng} / \mathrm{mL})$ response with different doses of TNF- $\alpha(1,20,100 \mathrm{ng} / \mathrm{mL})$ and IL- $1 \beta(1,20,100 \mathrm{ng} / \mathrm{mL})$ using MCP-1 as readout as this chemokine is consistently released in response to LPS [14]. TNF- $\alpha$, at a concentration of $100 \mathrm{ng} / \mathrm{mL}$, resulted in a significant increase of MCP-1 (Fig. 1), while IL- $1 \beta$ did not (data not shown). As the highest dose of TNF- $\alpha(100 \mathrm{ng} / \mathrm{mL})$ consistently induced MCP-1, it was chosen to evaluate the response to sterile inflammation in the subsequent experiments.

\section{Galectin-3 Effect on MCP-1 Release}

To evaluate if galectin-3 had any effect on microglia response independently or under inflammatory conditions, we continued to investigate the effect on MCP-1 release from microglia exposed to different doses of galectin-3 separately or together with LPS $(10 \mathrm{ng} / \mathrm{mL})$ or TNF- $\alpha(100 \mathrm{ng} / \mathrm{mL})$. The choice of galectin-3 doses was based on previous results from neutrophil stimulation ex- periments [30], and as contradictory effects of galectin-3 have been reported and to exclude that such effects were dose-dependent, we performed experiments with 3 different doses of galectin-3 $(100,50$, and $5 \mu \mathrm{g} / \mathrm{mL})$. Since it has been suggested that galectin-3 regulates LPS responses by binding directly to the LPS molecule [31], a pilot study was performed where galectin- 3 was added $1 \mathrm{~h}$ before, at the same time, or $1 \mathrm{~h}$ after LPS. No differences were seen in MCP-1 response (data not shown), and in the following experiments, LPS or TNF- $\alpha$ and galectin-3 were added together. In summary, galectin- 3 on its own did not induce MCP-1 at any concentration, but higher concentrations significantly reduced the MCP-1 response to TNF- $\alpha$, and there was a similar trend following LPS (Fig. 1), suggesting that galectin-3 could modulate the inflammatory response under both sterile and infectious inflammatory conditions. 


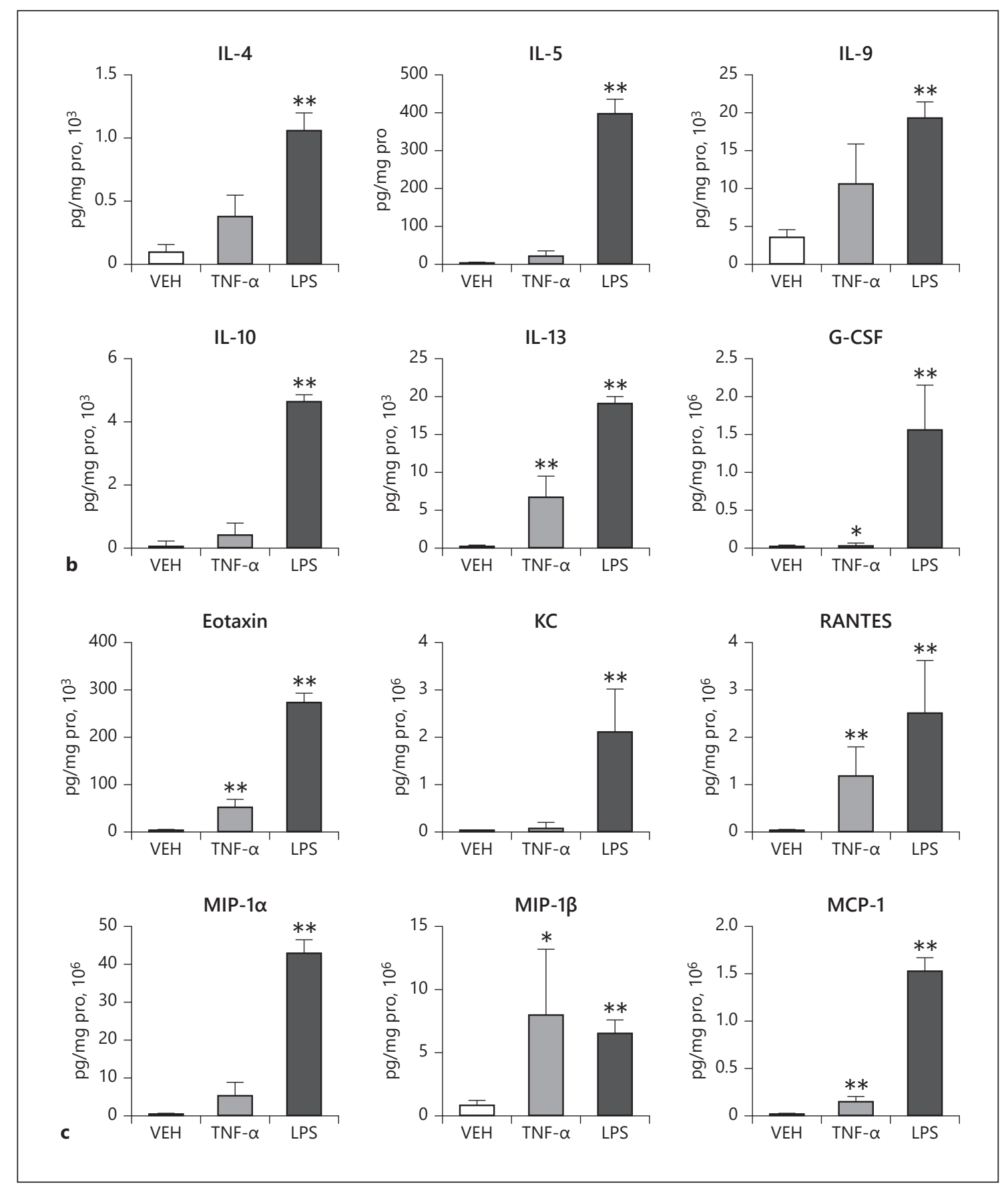

Fig. 3. Inflammation is induced in microglia following both LPS and TNF- $\alpha$ stimulation. Proteins were measured by 23-plex immunoassay, in cell culture medium from primary microglia cultures treated with LPS $(10 \mathrm{ng} / \mathrm{mL})$ or TNF- $\alpha(100 \mathrm{ng} / \mathrm{mL})$, for 24 $\mathrm{h}$. The results are divided into mainly pro-inflammatory cytokines (a), mainly anti-inflammatory cytokines (b), and chemokines (c) and only proteins with significant alterations are shown. The results are presented as mean (+SEM) and analyzed by one-way ANOVA, followed by Dunnet's correction; ${ }^{*} p<0.05 ;{ }^{* *} p<0.01$ vehicle versus treatment with LPS or TNF- $\alpha$. The figure presents the average of 3 independent repeats with 2 samples representing 6 animals for each repeat. 

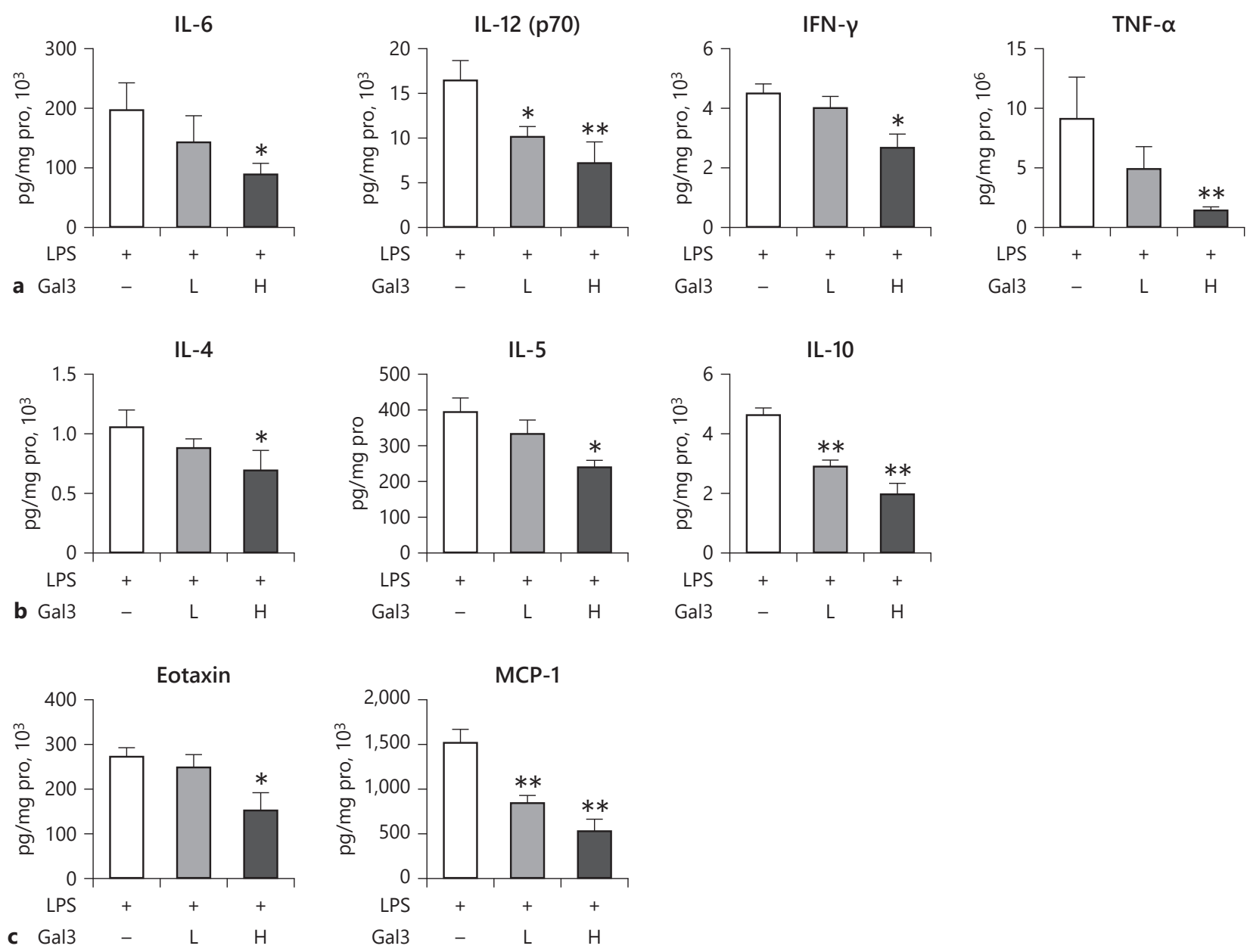

Fig. 4. Galectin-3 reduces the microglial inflammatory response to LPS. Proteins were measured by 23-plex immunoassay in cell culture medium from primary microglia cultures treated with LPS (10 $\mathrm{ng} / \mathrm{mL})$ alone or in combination with high dose $(H=100 \mu \mathrm{g} / \mathrm{mL})$ or low dose $(L=5 \mu \mathrm{g} / \mathrm{mL})$ of galectin-3. The results are divided into mainly pro-inflammatory cytokines (a), mainly anti-inflammatory cytokines (b), and chemokines (c) and only proteins with

Fig. 5. Galectin-3 reduces microglial inflammatory response to TNF- $\alpha$. Proteins were measured by 23-plex immunoassay in cell culture media from primary microglia cultures treated with TNF- $\alpha$ $(100 \mathrm{ng} / \mathrm{mL})$ alone or in combination with high dose $(H=100 \mu \mathrm{g} /$ $\mathrm{mL})$ or low dose $(L=5 \mu \mathrm{g} / \mathrm{mL})$ of galectin-3. The results are divided into mainly pro-inflammatory cytokines (a), mainly antiinflammatory cytokines (b), and chemokines (c), and only pro- significant alterations are shown. Results are presented as mean $(+$ SEM) and analyzed by one-way ANOVA followed by Dunnet's correction; ${ }^{*} p<0.05 ;{ }^{* *} p<0.01$ for LPS $(10 \mathrm{ng} / \mathrm{mL})$ only versus treatment with low-dose $(L=5 \mu \mathrm{g} / \mathrm{mL})$ or high-dose $(H=100 \mu \mathrm{g} /$ $\mathrm{mL})$ galectin-3. The figure presents the average of 3 independent repeats with 2 samples representing 6 animals for each repeat. teins with significant alterations are shown. Results presented as mean $(+$ SEM) and analyzed by one-way ANOVA followed by Dunnet's correction; ${ }^{*} p<0.05$; ${ }^{* *} p<0.01$ for TNF- $\alpha(100 \mathrm{ng} / \mathrm{mL})$ only versus treatment with low-dose $(L=5 \mu \mathrm{g} / \mathrm{mL})$ or high-dose $(H=100 \mu \mathrm{g} / \mathrm{mL})$ galectin-3. The figure presents the average of 3 independent repeats with 2 samples representing 6 animals for each repeat.

(For figure see next page.) 


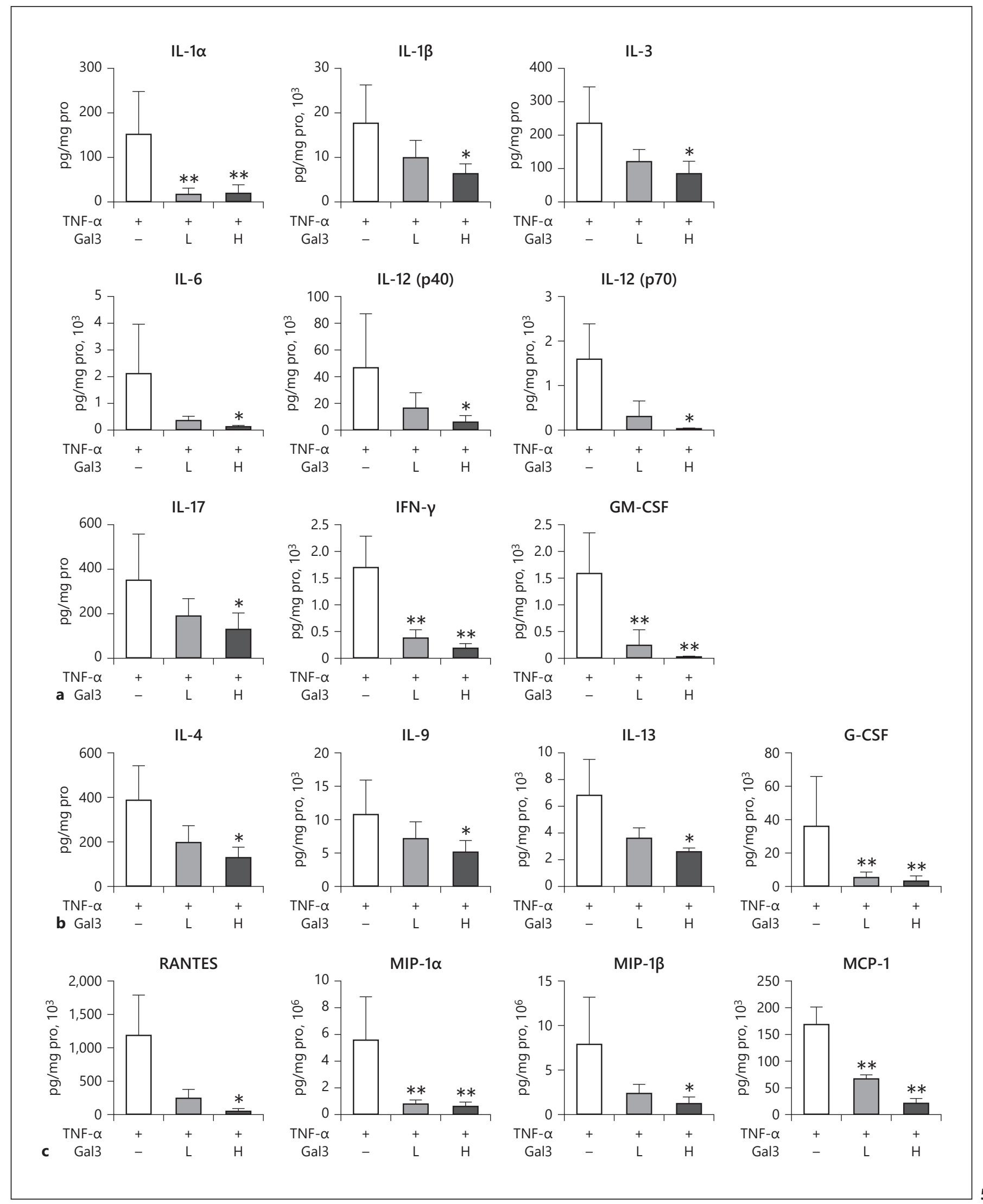




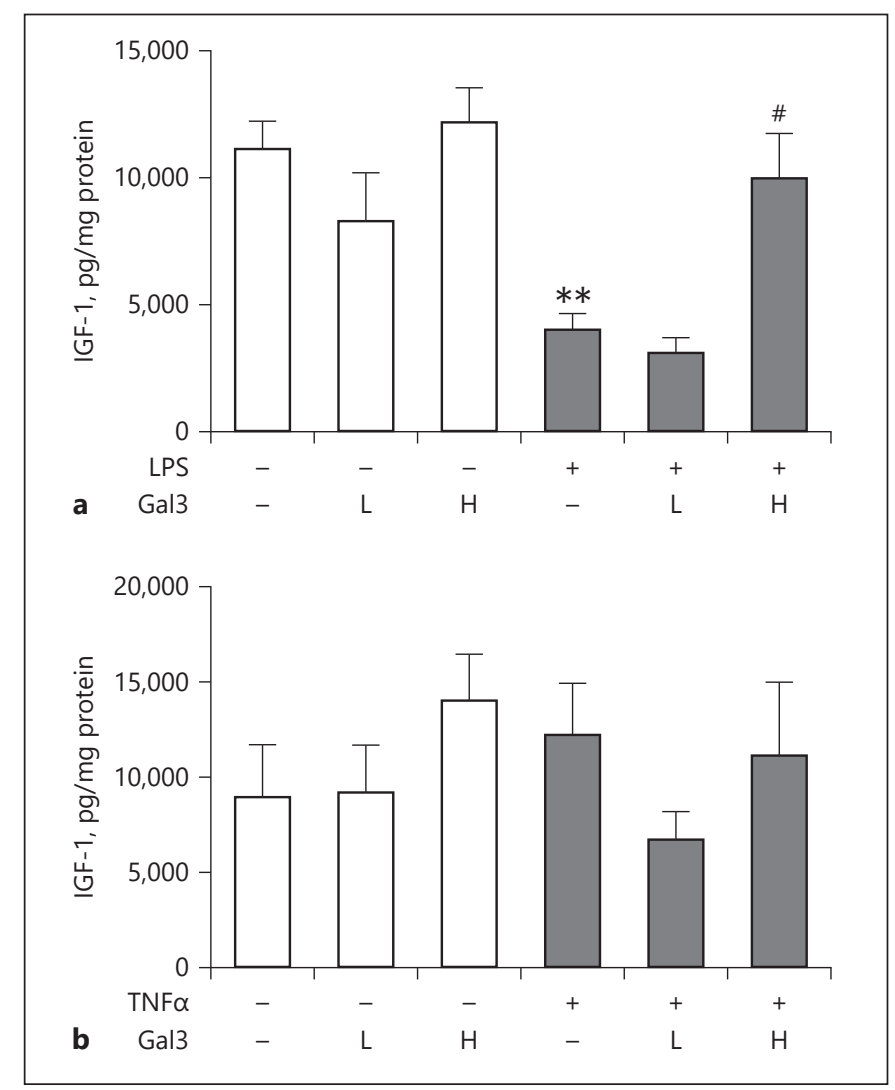

Fig. 6. Galectin-3 normalizes microglial IGF-1 production following LPS exposure. IGF-1 production was analyzed by ELISA in cell culture medium from microglia treated with LPS $(10 \mathrm{ng} / \mathrm{mL})$ alone or LPS $(10 \mathrm{ng} / \mathrm{mL})$ in combination with low dose $(L=5 \mu \mathrm{g} / \mathrm{mL})$ or high dose $(H=100 \mu \mathrm{g} / \mathrm{mL})$ of galectin-3 (a) or TNF- $\alpha(100 \mathrm{ng} / \mathrm{mL})$ alone, or in combination with low dose $(L=5 \mu \mathrm{g} / \mathrm{mL})$ or high dose $(H=100 \mu \mathrm{g} / \mathrm{mL})$ of galectin-3 (b). Results are presented as mean $(+$ SEM) and analyzed by one-way ANOVA followed by Bonferroni's correction; ${ }^{* *} p<0.01$ for Veh versus LPS and ${ }^{*} p<0.05$ for LPS versus LPS with high dose of galectin-3 $(H=100 \mu \mathrm{g} / \mathrm{mL})$. The figure presents the average of 3 independent repeats with 2 samples representing 6 animals for each repeat. IGF-1, insulin-like growth factor.

\section{Evaluation of Cell Toxicity}

To exclude that responses to galectin-3, LPS, or TNF- $\alpha$ were affected by cell death, toxicity was evaluated by LDH release into the cell culture medium. No increased cell death was seen for any of the compounds used (Fig. 2).

\section{Both LPS and TNF- $\alpha$ Induce Comprehensive \\ Inflammatory Responses in Microglia}

To evaluate the overall microglia response to infectious and sterile inflammation, LPS (10 ng/mL) and TNF- $\alpha(100 \mathrm{ng} / \mathrm{mL})$ stimulations were compared by using a 23-plex cytokine assay. The assay included (i) main- ly pro-inflammatory cytokines (IL- $1 \alpha$, IL- $1 \beta$, IL-2, IL-3, IL-6, IL-12p40, IL-12p70, IL-17, IFN- $\gamma$, TNF- $\alpha$, GMCSF), (ii) mainly anti-inflammatory cytokines (IL-4, IL5, IL-9, IL-10, IL-13, G-CSF), and (iii) chemokines (eotaxin, KC, RANTES, MCP-1, MIP-1 $\alpha$, MIP-1 $\beta$ ). LPS significantly upregulated $9 / 11$ pro-inflammatory cytokines (Fig. 3a), 6/6 anti-inflammatory cytokines (Fig. 3b), and 6/6 chemokines (Fig. 3c). A similar response was observed after TNF- $\alpha$, with upregulation of $9 / 10$ pro-inflammatory cytokines (TNF- $\alpha$ measurement not included, Fig. 3a), 2/6 anti-inflammatory cytokines (Fig. 3b), and $4 / 6$ chemokines (Fig. 3c). A similar nonspecific inflammatory response including both pro- and anti-inflammatory proteins was thus seen after sterile and infectious challenges, respectively, but the response to TNF- $\alpha$ was generally less pronounced than that to LPS at the given doses.

Galectin-3 modulates the inflammatory response in microglia following both infectious and sterile stimuli in vitro. To evaluate the immunomodulatory effect of galectin-3, the effect of high $(100 \mu \mathrm{g} / \mathrm{mL})$ and low $(5 \mu \mathrm{g} / \mathrm{mL})$ concentrations of galectin-3 was investigated in microglia cultures stimulated by either LPS or TNF- $\alpha$. The effect was evaluated by a 23-plex cytokine assay, as described earlier. The high galectin-3 concentration significantly dampened the response to LPS for 4/11 pro-inflammatory cytokines (Fig. 4a), 3/6 anti-inflammatory cytokines (Fig. 4b), and 2/6 chemokines (Fig. 4c). The low concentration of galectin-3 reduced the induction of IL-12 (p70), IL-10, and MCP-1. In TNF- $\alpha$-stimulated cultures, the high concentration of galectin- 3 reduced the response of 9/10 pro-inflammatory cytokines (Fig. 5a), 4/6 anti-inflammatory cytokines (Fig. 5b), and $4 / 6$ chemokines (Fig. 5c). The low concentration of galectin-3 reduced the response to TNF- $\alpha$ for $3 / 10$ pro-inflammatory cytokines (Fig. 5a), 1/6 anti-inflammatory cytokines (Fig. 5b), and $2 / 6$ chemokines (Fig. 5 c). Galectin-3 alone did not induce any of the proteins measured, irrespective of dose (data not shown). Thus, in spite of having no effect on its own, galectin-3 modulated the microglia response to infectious as well as sterile stimuli, resulting in an overall dampening of cytokine and chemokine release.

\section{Galectin-3 Effect on IGF-1 Production in vitro}

In adult models of brain ischemia, galectin-3 is co-expressed with IGF-1 in microglia, suggesting that galectin-3 effects on brain injury may also be mediated by growth factors with potentially protective properties [23]. The effects of galectin-3 on IGF-1 production, under normal and inflammatory conditions (LPS and TNF- $\alpha$ ), were 

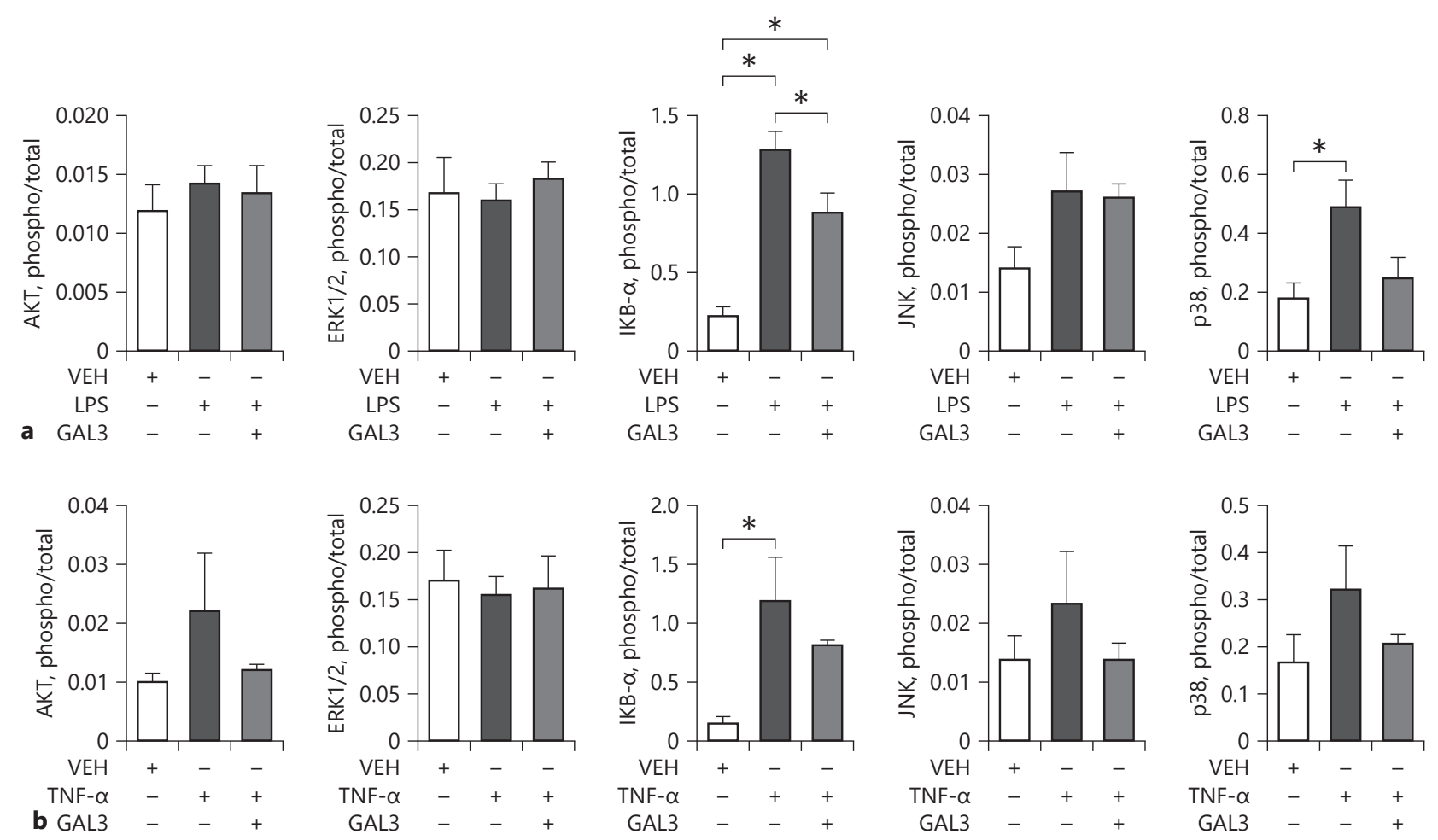

Fig. 7. Galectin-3 reduces IкB- $\alpha$ expression in microglia following LPS. Microglia stimulated by LPS (a) or TNF- $\alpha(\mathbf{b})$, and in combination with galectin-3 (100 $\mu \mathrm{g} / \mathrm{mL})$ were analyzed using a phos- phoprotein panel consisting of ERK1/2, JNK, p38, IKB- $\alpha$, and AKT. Results are presented as mean (+SEM) and analyzed by oneway ANOVA followed by Bonferroni's correction; ${ }^{*} p<0.05$. therefore evaluated. In contrast to findings for cytokines and chemokines, the galectin-3 immunomodulatory effect on IGF-1 production differed between infectious and sterile inflammatory conditions. LPS significantly reduced the baseline production of IGF-1, and the reduction was reversed by the high concentration of galectin-3 (Fig. 6a). Baseline IGF-1 production was not affected by TNF- $\alpha$ (Fig. 6b), neither did galectin-3 by itself or in combination with TNF- $\alpha$ affect IGF-1 levels (Fig. 6b).

\section{Effect of Galectin-3 on MAP Kinase Production and NF- $k B$ Pathway in vitro}

To further investigate galectin-3 effects on downstream inflammatory modulators, we analyzed the phosphorylation of ERK, JNK, and p38; the pro-survival serine/threonine-specific protein kinase AKT; and the general inflammatory conductor nuclear factor B inhibitor (IkBa) (Fig. 7). LPS did not by itself nor in combination with galectin-3 affect levels of phosphorylated AKT, ERK1/2, or JNK. On the other hand, LPS markedly induced expression of IkBa and $\mathrm{p} 38$. The addition of galec- tin-3 prevented the expression of LPS-induced p38 and significantly reduced the IkBa phosphorylation (Fig. 7a). A similar trend was observed in TNF- $\alpha$-stimulated microglia (Fig. 7b).

\section{Galectin-3 Deficiency Does Not Affect Microglia Activation following LPS-Sensitized HI in vivo}

As galectin-3 reduced inflammatory responses in microglia in vitro, we also investigated microglia response in vivo in wild-type and galectin-3-deficient mice in a model for neonatal brain injury encompassing an infectious challenge (LPS + HI). Two-way ANOVA indicated no effect of sex and genetic background (galectin-3 deficiency) on microglia volume and sphericity changes $\left(F_{(37,1)}=1.188, p=0.283, F_{(37,1)}=2.974, p=0.093\right.$, $F_{(37,1)}=0.966, p=0.332, F_{(37,1)}=0.117, p=0.734$, Fig. 8).

\section{Galectin-3 Deficiency Does Not Affect Brain Injury following LPS-Sensitized HI in vivo}

Next, we evaluated the effect of galectin-3 deficiency on neonatal brain injury following LPS + HI. Contrary to 


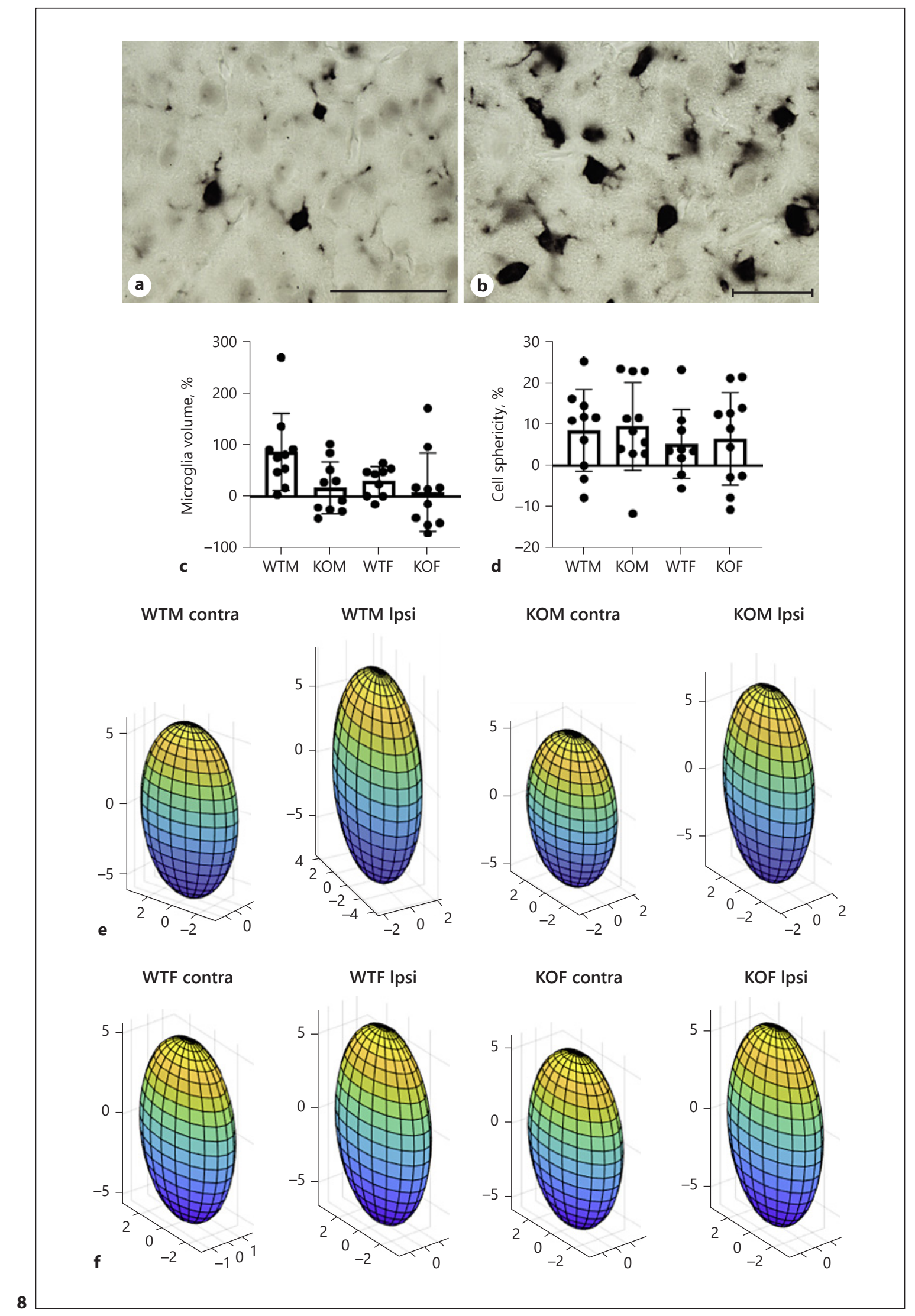

(For legend see next page.) 
our previous findings where galectin- 3 contributed to injury after HI, no effects of galectin-3 deficiency or sex on grey matter injury (loss of MAP-2 staining $\left(F_{(38,1)}=0.731\right.$, $\left.p=0.398, F_{(38,1)}=0.177, p=0.677\right)$ or white matter injury (loss of MBP staining, data not shown) after HI injury together with an infectious challenge were observed (Fig. 9).

\section{Discussion}

This study is the first to describe an immunomodulatory effect of galectin-3 on both infectious and sterile inflammation in microglia in vitro. We show that while galectin-3, irrespective of dose, has no independent effect on microglia, it modulates inflammatory activation by re-

Fig. 9. Galectin-3 deficiency does not affect grey matter injury after neonatal LPS-sensitized HI injury. The combination of LPS and HI was used to induce brain injury in PND9 mice, and extent of injury was investigated 1 week later at PND16. Representative images of brain sections stained with MAP-2 at the hippocampal level in male wild-type (a), male galectin-3-deficient (b), female-wild-type (c), female galectin3-deficient (d) mice. Scale bar, $2.5 \mathrm{~mm}$. e The percentage of tissue volume loss in the ipsilateral injured hemisphere was calculated in MAP-2-stained brain sections. WTM, wild-type male; KOM, galectin3-deficient male; WTF, wild-type female; KOF, galectin-3-deficient female. Statistical analysis was performed using 2-way ANOVA, $n=9-12$ /group. HI, hypoxicischemic; PND, postnatal day.

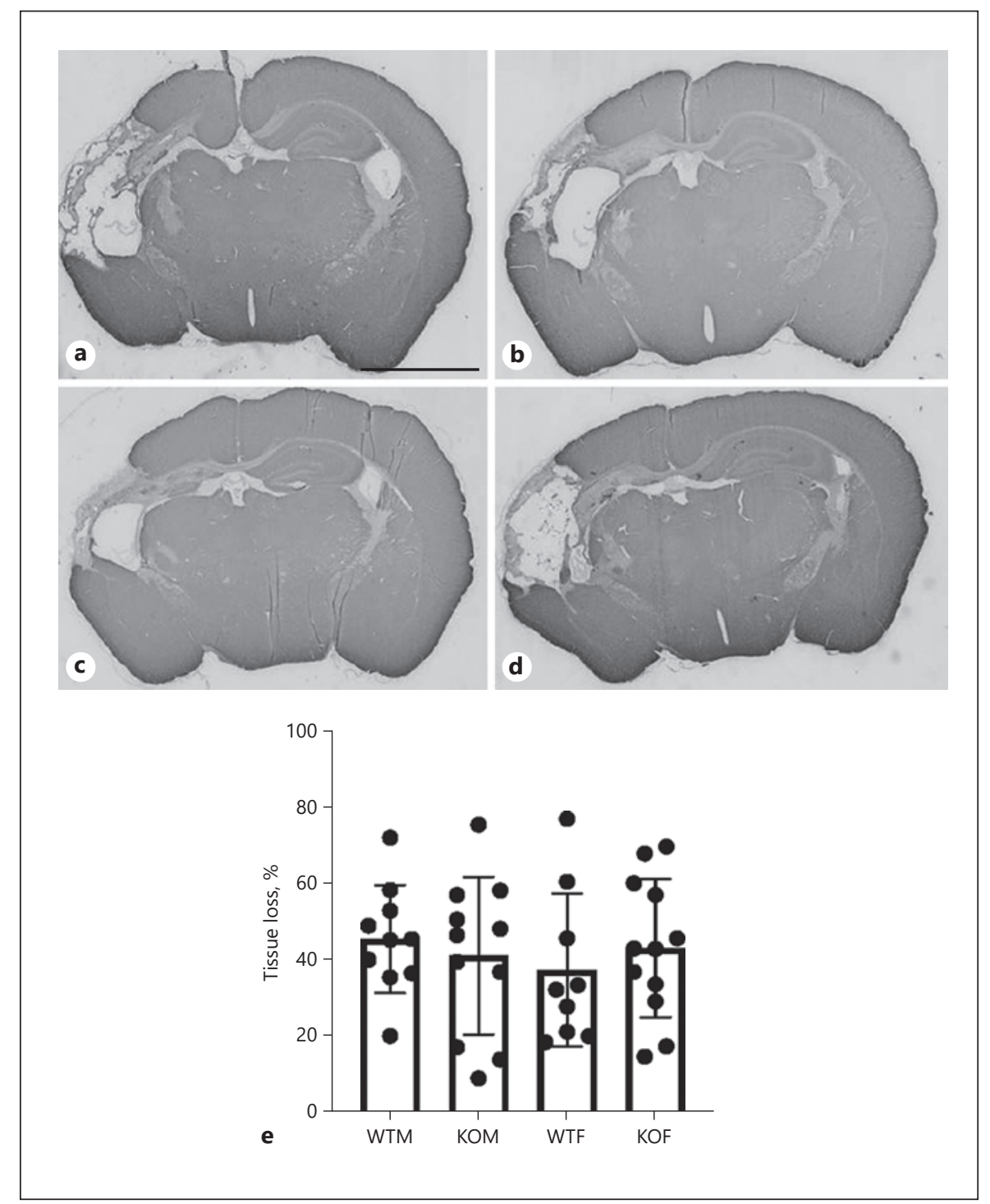

Fig. 8. Galectin-3 deficiency does not affect microglia response after neonatal LPS-sensitized HI injury. Representative images of Iba1-positive microglia in contralateral (a) and ipsilateral (b) hemispheres 1 week following the combination of LPS and HI. Scale bar, $30 \mu \mathrm{m}$. Percentage change of microglia cell volume (c) and sphericity (d) in the ipsilateral hemisphere compared to contralateral hemisphere. e, $\mathbf{f}$ Three-dimensional ellipsoid plots of mi- croglia ellipsoid shape in ipsilateral (ipsi) and contra hemispheres were generated for each group. WTM, wild-type male; KOM, galectin-3-deficient male; WTF, wild-type female; KOF, galectin3 -deficient female. Statistical analysis was performed using 2-way ANOVA, $n=9-12$ /group. HI, hypoxic-ischemic; contra, contralateral; ipsi, ipsilateral. 
ducing cytokine and chemokine responses and activation of the NF-kB pathway and p38 under inflammatory conditions in vitro. The general pattern of a dampened inflammatory responses was similar under infectious and sterile inflammatory conditions, but galectin-3 restored depressed levels of the potentially neuroprotective growth factor IGF-1 only following LPS-induced inflammation. However, in contrast to our previous findings, galectin-3 deficiency did not affect microglia responses or brain injury following an animal model of combined infection and $\mathrm{HI}$.

Both clinical and experimental investigations give strong support to a link between inflammatory responses in the brain and perinatal brain injury. There is a marked cytokine response in the human brain after birth asphyxia, which is related to the degree of HI encephalopathy in the infant [32]. Infections that elicit a systemic inflammatory response in the infant may directly harm the immature white matter [33] or render the infant susceptible to additional insults $[5,34]$. Similarly, in animal models, LPS-induced inflammation is associated with brain injury in fetal sheep [35], rabbits [36], and rodents [37] and the combination of infectious insults and HI worsens outcome further [38]. Brain injury following sterile insults, such as HI, is also associated with a strong inflammatory response in the rodent brain $[2,39]$. However, it has been highlighted that depending on the timing of infection and its associated inflammatory response, decreased risk of injury in newborns can also been observed [40], and animal studies show that LPS under some circumstances can have a protective preconditioning effect on neonatal HI brain injury [41].

The mechanisms and balance between injurious and beneficial inflammatory features may differ between sterile and infectious inflammation, and any therapeutic intervention aimed at modulating the inflammatory response must take this into consideration. Thus, we compared the effects of microglia stimulation by LPS and TNF- $\alpha$ as models for infectious and sterile inflammation, respectively. LPS is a constituent of the outer cell wall of Gram-negative bacteria and has well-described pro-inflammatory effects on microglia mediated by toll-like receptor (TLR)-4 [14]. TNF- $\alpha$ is part of the inflammatory cascade in the brain after sterile insults, such as neonatal $\mathrm{HI}$, and may contribute to injury [42]. TNF- $\alpha$ elicits inflammatory responses through mechanisms independent of TLRs, thus representing an alternative sterile, inflammatory activation. It has previously been shown that noninfectious challenges in vitro, such as oxygen-glucose deprivation, result in cytokine response similar to that seen after LPS activation but with different intensity of response [43]. In our study, we found that TNF- $\alpha$ elicits an inflammatory response pattern in primary microglia that closely resembles that seen after LPS stimulation, but with a generally lower magnitude at the doses used. We cannot exclude that higher doses of TNF- $\alpha$ may provoke a stronger response however even a low dose of TNF- $\alpha$ $(10 \mathrm{ng} / \mathrm{mL})$ gives a robust response in murine bone marrow macrophages and promotes rapid NF- $\kappa \mathrm{B}$ nuclear translocation [44] and very low doses $(<5 \mathrm{ng} / \mathrm{mL})$ of TNF- $\alpha$ induces a solid IL-10 mRNA response in monocytes [45] and increased IL-10 protein, similar to LPS, in human microglial cells [46].

Galectin-3 produced by microglia cells has emerged as a potentially important immunomodulator with pro- as well as anti-inflammatory properties and was recently suggested to be a key molecule, via NF-kB mechanisms, in the switch between beneficial and detrimental effects of microglia [47]. In our in vitro study, we found no microglia response to stimulation with galectin-3 alone, irrespective of dose. This is in contrast to other findings of a cytokine-like stimulatory effect of galectin-3 in primary microglia cultures [20]. The authors report that galectin-3 in doses corresponding to the lowest doses used in our study $(5 \mu \mathrm{g} / \mathrm{mL})$ stimulates the transcription of proinflammatory, but not anti-inflammatory genes, in rat microglia cultures and that lower doses $(2.5 \mu \mathrm{g} / \mathrm{mL})$ induced up to 30 -fold increases of pro-inflammatory cytokines TNF- $\alpha$, IL-12, and IL- $1 \beta$ when analyzed by ELISA at $18 \mathrm{~h}$. The different findings in our study are puzzling since we analyzed more than 10 pro-inflammatory cytokines with a similar method, at a similar time-point after stimulation, and with doses only slightly higher than those used by Jeon and colleagues [20]. There may however be species differences since we used mouse instead of rat cultures. The possibility of a dose-dependent reversed effect is also intriguing based on the contradictory effects reported for galectin-3 in vivo. However, no such dose-dependent reversed effects were found in our study despite 20-fold differences in galectin-3 doses used.

A main finding in this study was that galectin-3 modulated the microglia response to LPS and TNF- $\alpha$ with a significant reduction of pro- and anti-inflammatory cytokines as well as chemokines released under inflammatory conditions. In support, we also found a significant effect of galectin-3 on phosphorylation of IкB-a, while there were no major effects on MAP kinases, apart from p38. The phosphorylation of IkB-a leads to its degradation and subsequent nuclear translocation of NF- $\mathrm{kB}$ to allow cytokine gene transcription, which is likely to have 
contributed to the cytokine/chemokine responses [48]. The effect on cytokines and chemokines was most pronounced with the highest dose of galectin-3 suggesting a dose-dependent response. The dampening effect of galectin-3 was more pronounced for TNF- $\alpha$-stimulated microglia, which may be explained by the generally lower inflammatory response elicited in this model for sterile inflammation. This is further supported by the dose-related effects, suggesting that the inhibitory effect of galectin-3 may be enhanced by a relatively higher galectin-3 concentration in relation to the original inflammatory response. An infection-specific inhibitory effect of galectin-3 on LPS-induced inflammation has previously been reported [49]. The authors showed that galectin-3-deficient macrophages have an exaggerated production of pro-inflammatory cytokines IL-6, IL-12, and TNF- $\alpha$ following LPS stimulation. They showed that the effects were dependent on LPS interaction with TLR4 and downstream signaling. The effects could be reversed by preincubating LPS with galectin-3, and the authors suggested that the immunomodulatory effect was mediated by galectin-3 directly binding to LPS. More recent data however suggest that galectin-3 instead binds to TLR4 [50]. Our data directly contradict these hypotheses since we demonstrate a similar immunomodulatory effect in LPS and TNF- $\alpha$-induced inflammation. The inflammatory effect of TNF- $\alpha$ is not mediated by TLRs, and a direct binding of galectin-3 to TNF- $\alpha$ is less likely, suggesting other, possibly intracellular, mechanisms underlying the inhibitory effect of galectin-3.

A main difference between LPS- and TNF- $\alpha$-induced responses was seen for IGF-1 release, where only LPSinduced inflammation reduced the endogenous IGF-1 production. IGF-1 is a growth factor expressed in the brain after $\mathrm{HI}$ in juvenile animals [51], and it is protective in neonatal [52], and adult [53] HI injury models. Interestingly, in adult animals, a subpopulation of proliferating microglia co-expressing galectin-3 and IGF-1 has protective properties after stroke [23]. Although our in vitro study fails to show a clear relation between galectin-3 and IGF-1 under noninfectious conditions, it still suggests that galectin-3 may help regulate endogenous microglial IGF-1 production in infectious inflammation.

In the present study, we found that the overall effect of administration of galectin-3 on microglia inflammatory reaction in vitro was a general dampening of the response with suppression of pro-inflammatory, potentially neurotoxic, cytokines and anti-inflammatory, potentially neuroprotective, cytokines. Restoration of suppressed IGF-1 levels, suggesting a more robust neuroprotective

Galectin-3 Modulates Microglia

Inflammation effect was found in the infectious setting only. These findings suggest multiple immunomodulatory effects of galectin-3, which is in accordance with varying, and partly contradictory effects, of galectin-3 in in vivo models of brain injury. In adult brain injury models, galectin-3-expressing microglia are neuroprotective [23], and in neonatal stroke models, galectin-3 deficiency is accompanied by increased injury and specific alterations in cytokine and chemokine response [24]. Our previous findings in models for neonatal HI injury suggest however that galectin-3 could also contribute to injury [17]. The protection seen after $\mathrm{HI}$ in newborn mice lacking galectin-3 was not accompanied by any changes in early pro-inflammatory cytokine or IGF-1 expression. Reduced levels of MMP-9 together with an increased number of microglia cells in galectin-3-deficient animals suggest however that galectin-3 was able to modulate the microglia phenotype in vivo under these sterile inflammatory conditions. In contrast, we now show that microglia volume (hypertrophy) and shape indicative of activation (sphericity) are not different between wild-type and galectin-3-deficient mice when HI was combined with LPS as an infectious challenge. Neither was injury in grey and white matter affected by genetic background. The disparate findings of protective or injurious properties confirm the complex role of galectin-3 in the brain. Age-dependent effects may be related to the presence of different subpopulations of microglial cells with different characteristics in adult compared with immature brain following injury [54]. Further, differences in proliferating cells and contribution of peripheral cells to injury may explain diverse outcome in different models of neonatal brain damage [55]. The strong galectin-3 effect on reversing the LPS-mediated IGF-1 suppression in vitro also suggests that galectin-3 may have specific effects in perinatal brain injury models that include infectious insults. A limitation of the current study is that we have not determined pro-survival factors, such as IGF-1 and cytokine responses in vivo. Neither does the study investigate potential effects of galectin-3 deficiency on behavior following LPS + HI.

\section{Conclusion}

In summary, we show for the first time that administration of galectin-3 modulates the microglia phenotypes following both infectious and sterile inflammation by reducing the cytokine and chemokine responses under these inflammatory conditions in vitro. The effect was similar under infectious and sterile inflammatory condi- 
tions, suggesting that galectin-3 regulates inflammation not just by binding to LPS or its receptor TLR4. Galectin-3 also restores IGF-1 levels reduced by LPS-induced inflammation, while contrary to findings after neonatal HI, galectin-3 did not contribute to injury or affect microglia responses when an infectious challenge was included in the injury model. Our findings indicate that galectin-3 has complex immunomodulatory, properties and brain maturity and the inflammatory setting have to be taken into consideration.

\section{Acknowledgements}

We thank Dr. Hayde Bolouri for analysis of phosphoproteins.

\section{Statement of Ethics}

All animal procedures were carried out in accordance with Swedish Guidelines for the Care and Use of Laboratory Animals and were approved by the Animal Ethics Committee in Gothenburg (No. 374-2009).

\section{Conflict of Interest Statement}

The authors have no conflicts of interest to declare.

\section{Funding Sources}

This work was supported by Swedish Research Council (VR2017-01409, C.M.), Public Health Service at the Sahlgrenska University Hospital (ALFGBG-722491, C.M./K.S.), Region Västra Götaland, for Collaborative Research (VGFOUREG-932182, K.S.), the Swedish Brain Foundation (FO2017-0063; FO20190270, C.M.), Torsten Söderberg Foundation (M98/15, C.M.), Wilhelm and Martina Lundgren Foundation (C.M. and V.G.), and Åhlen Foundation (C.M.), Märta Lundqvist Foundation (V.G.).

\section{Author Contributions}

K.S., C.M., K.L.B., and A.K.-B. contributed with conception and design of the work; W.W., A.H.R., P.S., S.N., M.A., and V.G. contributed with acquisition, analysis, and interpretation of data. K.S. and C.M. drafted the manuscript, and all authors critically reviewed the manuscript before submission.

\section{References}

1 Hagberg H, Mallard C, Ferriero DM, Vannucci SJ, Levison SW, Vexler ZS, et al. The role of inflammation in perinatal brain injury. Nat Rev Neurol. 2015 Apr;11(4):192-208.

2 Hedtjarn M, Mallard C, Hagberg H. Inflammatory gene profiling in the developing mouse brain after hypoxia-ischemia. J Cereb Blood Flow Metab. 2004 Dec;24(12):1333-51.

3 Eklind S, Hagberg H, Wang X, Sävman K, Leverin $A L$, Hedtjärn $M$, et al. Effect of lipopolysaccharide on global gene expression in the immature rat brain. Pediatr Res. 2006 Aug; 60(2):161-8.

4 Strunk T, Inder T, Wang X, Burgner D, Mallard C, Levy O. Infection-induced inflammation and cerebral injury in preterm infants. Lancet Infect Dis. 2014 Aug;14(8):751-62.

5 Nelson KB, Grether JK. Potentially asphyxiating conditions and spastic cerebral palsy in infants of normal birth weight. Am J Obstet Gynecol. 1998 Aug;179(2):507-13.

6 Mallard C, Wang X, Hagberg H. The role of Toll-like receptors in perinatal brain injury. Clin Perinatol. 2009 Dec;36(4):763-72, v-vi.

7 Bona E, Andersson AL, Blomgren K, Gilland E, Puka-Sundvall M, Gustafson K, et al. Chemokine and inflammatory cell response to hypoxia-ischemia in immature rats. Pediatr Res. 1999 Apr;45(4 Pt 1):500-9.

8 Smith PL, Hagberg H, Naylor AS, Mallard C. Neonatal peripheral immune challenge activates microglia and inhibits neurogenesis in the developing murine hippocampus. Dev Neurosci. 2014;36(2):119-31.
9 Bonestroo HJ, Heijnen CJ, Groenendaal F, van Bel F, Nijboer CH. Development of cerebral gray and white matter injury and cerebral inflammation over time after inflammatory perinatal asphyxia. Dev Neurosci. 2015;37(1): 78-94.

10 Hedtjarn M, Leverin AL, Eriksson K, Blomgren K, Mallard C, Hagberg H. Interleukin-18 involvement in hypoxic-ischemic brain injury. J Neurosci. 2002 Jul 15;22(14): 5910-9.

11 Svedin P, Hagberg H, Sävman K, Zhu C, Mallard C. Matrix metalloproteinase-9 gene knock-out protects the immature brain after cerebral hypoxia-ischemia. J Neurosci. 2007 Feb 14;27(7):1511-8.

12 Hedtjarn M, Mallard C, Iwakura Y, Hagberg H. Combined deficiency of IL-1beta18, but not IL-1alphabeta, reduces susceptibility to hypoxia-ischemia in the immature brain. Dev Neurosci. 2005 Mar-Aug;27(2-4):143-8.

13 Pierre WC, Smith PLP, Londono I, Chemtob S, Mallard C, Lodygensky GA. Neonatal microglia: the cornerstone of brain fate. Brain Behav Immun. 2017 Jan;59:333-45.

14 Chhor V, Le Charpentier T, Lebon S, Oré MV, Celador IL, Josserand J, et al. Characterization of phenotype markers and neuronotoxic potential of polarised primary microglia in vitro. Brain Behav Immun. 2013 Aug;32: $70-85$.
15 Faustino JV, Wang X, Johnson CE, Klibanov A, Derugin N, Wendland MF, et al. Microglial cells contribute to endogenous brain defenses after acute neonatal focal stroke. J Neurosci. 2011 Sep 7;31(36):12992-3001.

16 Walther M, Kuklinski S, Pesheva P, GuntinasLichius O, Angelov DN, Neiss WF, et al. Galectin-3 is upregulated in microglial cells in response to ischemic brain lesions, but not to facial nerve axotomy. J Neurosci Res. 2000 Aug 15;61(4):430-5.

17 Doverhag C, Hedtjärn M, Poirier F, Mallard C, Hagberg H, Karlsson A, et al. Galectin-3 contributes to neonatal hypoxic-ischemic brain injury. Neurobiol Dis. 2010 Apr;38(1): $36-46$.

18 Sano H, Hsu DK, Yu L, Apgar JR, Kuwabara I, Yamanaka T, et al. Human galectin-3 is a novel chemoattractant for monocytes and macrophages. J Immunol. 2000 Aug 15; 165(4):2156-64.

19 Colnot C, Ripoche MA, Milon G, Montagutelli X, Crocker PR, Poirier F. Maintenance of granulocyte numbers during acute peritonitis is defective in galectin-3-null mutant mice. Immunology. 1998 Jul;94(3):2906.

20 Jeon SB, Yoon HJ, Chang CY, Koh HS, Jeon SH, Park EJ. Galectin-3 exerts cytokine-like regulatory actions through the JAK-STAT pathway. J Immunol. 2010 Dec 01;185(11): 7037-46. 
21 MacKinnon AC, Farnworth SL, Hodkinson PS, Henderson NC, Atkinson KM, Leffler $\mathrm{H}$, et al. Regulation of alternative macrophage activation by galectin-3. J Immunol. $2008 \mathrm{Feb}$ 15;180(4):2650-8.

22 Hellstrom Erkenstam N, Smith PL, Fleiss B, Nair S, Svedin P, Wang W, et al. Temporal characterization of microglia/macrophage phenotypes in a mouse model of neonatal hypoxic-ischemic brain injury. Front Cell Neurosci. 2016;10:286.

23 Lalancette-Hebert M, Gowing G, Simard A, Weng YC, Kriz J. Selective ablation of proliferating microglial cells exacerbates ischemic injury in the brain. J Neurosci. 2007 Mar 7; 27(10):2596-605.

24 Chip S, Fernández-López D, Li F, Faustino J, Derugin N, Vexler ZS. Genetic deletion of galectin-3 enhances neuroinflammation, affects microglial activation and contributes to subchronic injury in experimental neonatal focal stroke. Brain Behav Immun. 2017 Feb;60: $270-81$.

25 Bolouri H, Sävman K, Wang W, Thomas A, Maurer N, Dullaghan E, et al. Innate defense regulator peptide 1018 protects against perinatal brain injury. Ann Neurol. 2014 Mar; 75(3):395-410.

26 Dean JM, Wang X, Kaindl AM, Gressens P, Fleiss B, Hagberg H, et al. Microglial MyD88 signaling regulates acute neuronal toxicity of LPS-stimulated microglia in vitro. Brain Behav Immun. 2010 Jul;24(5):776-83.

27 Stridh L, Mottahedin A, Johansson ME, Valdez RC, Northington F, Wang X, et al. Tolllike receptor-3 activation increases the vulnerability of the neonatal brain to hypoxiaischemia. J Neurosci. 2013 Jul 17;33(29): 12041-51.

28 Wang X, Stridh L, Li W, Dean J, Elmgren A, Gan L, et al. Lipopolysaccharide sensitizes neonatal hypoxic-ischemic brain injury in a MyD88-dependent manner. J Immunol. 2009 Dec 1;183(11):7471-7.

29 Ardalan M, Rafati AH, Nyengaard JR, Wegener G. Rapid antidepressant effect of ketamine correlates with astroglial plasticity in the hippocampus. Br J Pharmacol. 2017 Mar; 174(6):483-92.

30 Karlsson A, Follin P, Leffler H, Dahlgren C. Galectin-3 activates the NADPH-oxidase in exudated but not peripheral blood neutrophils. Blood. 1998 May 1;91(9):3430-8.

31 Mey A, Leffler H, Hmama Z, Normier G, Revillard JP. The animal lectin galectin-3 interacts with bacterial lipopolysaccharides via two independent sites. J Immunol. $1996 \mathrm{Feb}$ 15;156(4):1572-7.

32 Savman K, Blennow M, Gustafson K, Tarkowski E, Hagberg H. Cytokine response in cerebrospinal fluid after birth asphyxia. Pediatr Res. 1998 Jun;43(6):746-51.
33 Yoon BH, Jun JK, Romero R, Park KH, Gomez R, Choi JH, et al. Amniotic fluid inflammatory cytokines (interleukin-6, interleukin1 beta, and tumor necrosis factor-alpha), neonatal brain white matter lesions, and cerebral palsy. Am J Obstet Gynecol. 1997 Jul;177(1): 19-26.

34 Korzeniewski SJ, Romero R, Cortez J, Pappas A, Schwartz AG, Kim CJ, et al. A "multi-hit" model of neonatal white matter injury: cumulative contributions of chronic placental inflammation, acute fetal inflammation and postnatal inflammatory events. J Perinat Med. 2014 Nov;42(6):731-43.

35 Dean JM, van de Looij Y, Sizonenko SV, Lodygensky GA, Lazeyras F, Bolouri $\mathrm{H}$, et al. Delayed cortical impairment following lipopolysaccharide exposure in preterm fetal sheep. Ann Neurol. 2011 Nov;70(5):846-56.

36 Kannan S, Saadani-Makki F, Muzik O, Chakraborty P, Mangner TJ, Janisse J, et al. Microglial activation in perinatal rabbit brain induced by intrauterine inflammation: detection with 11C-(R)-PK11195 and small-animal PET. J Nucl Med. 2007 Jun;48(6):946-54.

37 Cai Z, Pan ZL, Pang Y, Evans OB, Rhodes PG. Cytokine induction in fetal rat brains and brain injury in neonatal rats after maternal lipopolysaccharide administration. Pediatr Res. 2000 Jan;47(1):64-72.

38 Eklind S, Mallard C, Leverin AL, Gilland E, Blomgren K, Mattsby-Baltzer I, et al. Bacterial endotoxin sensitizes the immature brain to hypoxic--ischaemic injury. Eur J Neurosci. 2001 Mar;13(6):1101-6.

39 Bonestroo HJ, Nijboer $\mathrm{CH}$, van Velthoven CT, Kavelaars A, Hack CE, van Bel F, et al. Cerebral and hepatic inflammatory response after neonatal hypoxia-ischemia in newborn rats. Dev Neurosci. 2013;35(2-3):197-211.

40 Jenster M, Bonifacio SL, Ruel T, Rogers EE, Tam EW, Partridge JC, et al. Maternal or neonatal infection: association with neonatal encephalopathy outcomes. Pediatr Res. 2014 Jul; 76(1):93-9.

41 Eklind S, Mallard C, Arvidsson P, Hagberg H. Lipopolysaccharide induces both a primary and a secondary phase of sensitization in the developing rat brain. Pediatr Res. 2005 Jul; 58(1):112-6.

42 Wixey JA, Reinebrant HE, Spencer SJ, Buller KM. Efficacy of post-insult minocycline administration to alter long-term hypoxia-ischemia-induced damage to the serotonergic system in the immature rat brain. Neuroscience. 2011 May 19;182:184-92.

43 Chock VY, Giffard RG. Development of neonatal murine microglia in vitro: changes in response to lipopolysaccharide and ischemialike injury. Pediatr Res. 2005 Apr;57(4):47580.
44 Abu-Amer Y, Ross FP, McHugh KP, Livolsi A, Peyron JF, Teitelbaum SL. Tumor necrosis factor-alpha activation of nuclear transcription factor-kappaB in marrow macrophages is mediated by c-Src tyrosine phosphorylation of Ikappa Balpha. J Biol Chem. 1998 Nov 06; 273(45):29417-23.

45 Wanidworanun C, Strober W. Predominant role of tumor necrosis factor-alpha in human monocyte IL-10 synthesis. J Immunol. 1993 Dec 15;151(12):6853-61.

46 Sheng WS, Hu S, Kravitz FH, Peterson PK, Chao CC. Tumor necrosis factor alpha upregulates human microglial cell production of interleukin-10 in vitro. Clin Diagn Lab Immunol. 1995 Sep;2(5):604-8.

47 Siew JJ, Chen HM, Chen HY, Chen HL, Chen $\mathrm{CM}$, Soong BW, et al. Galectin-3 is required for the microglia-mediated brain inflammation in a model of Huntington's disease. Nat Commun. 2019 Aug 2;10(1):3473.

48 Karin M, Ben-Neriah Y. Phosphorylation meets ubiquitination: the control of NF[kappa]B activity. Annu Rev Immunol. 2000; 18:621-63.

49 Li Y, Komai-Koma M, Gilchrist DS, Hsu DK, Liu FT, Springall T, et al. Galectin-3 is a negative regulator of lipopolysaccharide-mediated inflammation. J Immunol. 2008 Aug 15; 181(4):2781-9.

50 Burguillos MA, Svensson M, Schulte T, BozaSerrano A, Garcia-Quintanilla A, Kavanagh E, et al. Microglia-secreted galectin-3 acts as a toll-like receptor 4 ligand and contributes to microglial activation. Cell Rep. 2015 Mar 4; 10(9):1626-38

51 Beilharz EJ, Russo VC, Butler G, Baker NL, Connor B, Sirimanne ES, et al. Co-ordinated and cellular specific induction of the components of the IGF/IGFBP axis in the rat brain following hypoxic-ischemic injury. Brain Res Mol Brain Res. 1998 Aug 31;59(2):119-34.

52 Brywe KG, Mallard C, Gustavsson M, Hedtjärn M, Leverin AL, Wang X, et al. IGF-I neuroprotection in the immature brain after hypoxia-ischemia, involvement of Akt and GSK3beta? Eur J Neurosci. 2005 Mar;21(6): 1489-502.

53 Gluckman P, Klempt N, Guan J, Mallard C, Sirimanne E, Dragunow M, et al. A role for IGF-1 in the rescue of CNS neurons following hypoxic-ischemic injury. Biochem Biophys Res Commun. 1992 Jan 31;182(2):593-9.

54 Umekawa T, Osman AM, Han W, Ikeda T, Blomgren K. Resident microglia, rather than blood-derived macrophages, contribute to the earlier and more pronounced inflammatory reaction in the immature compared with the adult hippocampus after hypoxia-ischemia. Glia. 2015 Dec;63(12):2220-30.

55 Mallard C, Vexler ZS. Modeling ischemia in the immature brain: how translational are animal models? Stroke. 2015 Oct;46(10):3006-11. 